\title{
Article
}

Subscriber access provided by Northern Illinois University

\section{Improved Flavin-Based Catalytic Photo-Oxidation of Alcohols Through Intersystem Crossing Rate Enhancement}

Kirill A. Korvinson, George Nik Hargenrader, Jelena Stevanovic, Yun Xie, Jojo Joseph, Veselin Maslak, Christopher M. Hadad, and Ksenija D. Glusac

J. Phys. Chem. A, Just Accepted Manuscript • DOI: 10.1021/acs.jpca.6b08405 • Publication Date (Web): 26 Aug 2016

Downloaded from http://pubs.acs.org on August 31, 2016

\section{Just Accepted}

"Just Accepted" manuscripts have been peer-reviewed and accepted for publication. They are posted online prior to technical editing, formatting for publication and author proofing. The American Chemical Society provides "Just Accepted" as a free service to the research community to expedite the dissemination of scientific material as soon as possible after acceptance. "Just Accepted" manuscripts appear in full in PDF format accompanied by an HTML abstract. "Just Accepted" manuscripts have been fully peer reviewed, but should not be considered the official version of record. They are accessible to all readers and citable by the Digital Object Identifier (DOI®). "Just Accepted" is an optional service offered to authors. Therefore, the "Just Accepted" Web site may not include all articles that will be published in the journal. After a manuscript is technically edited and formatted, it will be removed from the "Just Accepted" Web site and published as an ASAP article. Note that technical editing may introduce minor changes to the manuscript text and/or graphics which could affect content, and all legal disclaimers and ethical guidelines that apply to the journal pertain. ACS cannot be held responsible for errors or consequences arising from the use of information contained in these "Just Accepted" manuscripts. 


\title{
Improved Flavin-based Catalytic Photo-oxidation of
}

\section{Alcohols Through Intersystem Crossing Rate}

\section{Enhancement}

\author{
Kirill A. Korvinson, ${ }^{\dagger}$ George N. Hargenrader, ${ }^{\dagger}$ Jelena Stevanovic, ${ }^{\S}$ Yun Xie, ${ }^{\dagger}$ Jojo Joseph, ${ }^{\star}$ \\ Veselin Maslak, ${ }^{\S}$ Christopher M. Hadad ${ }^{\ddagger}$ and Ksenija D. Glusac ${ }^{* \dagger}$ \\ $†$ Department of Chemistry, Center for Photochemical Sciences, Bowling Green State University, \\ Bowling Green, Ohio 43403, United States \\ †Department of Chemistry and Biochemistry, The Ohio State University, Columbus, OH 43210, \\ United States
}

$\S$ Faculty of Chemistry, University of Belgrade, Studentski Trg 12-16, Belgrade 11000, Serbia KEYWORDS flavin, photocatalysis, organocatalysis, benzaldehyde, oxidation.

\begin{abstract}
The triplet excited state formation efficiency in a flavin derivative was increased by the introduction of iodine into the molecular framework. The transient absorption measurements showed that the intersystem crossing rate was $1.1 \times 10^{10} \mathrm{~s}^{-1}$, significantly faster than in the parent flavin compound. Furthermore, the photocatalytic efficiency of iodo-flavin was evaluated using
\end{abstract}


the oxidation of benzyl alcohol as a model reaction. The benzaldehyde product yields were higher when iodo-flavin was used as a photocatalyst, showing that the increased triplet yield directly translates into improved photocatalysis. The iodo-flavin catalyst also allowed the use of higher substrate concentrations (since the undesired electron transfer from singlet excited state was minimized), which is expected to improve the practical aspects of photocatalysis by flavins.

\section{Introduction}

Flavin-based monooxygenases and oxidases are exceptionally efficient in activating molecular oxygen towards catalytic oxidation of a number of organic substrates. ${ }^{1-6}$ While monooxygenases insert atomic oxygen into a substrate $(\mathrm{S})$ by catalyzing the reaction $\mathrm{S}+\mathrm{O}_{2}+\mathrm{NADH}+\mathrm{H}^{+} \rightarrow \mathrm{SO}$ $+\mathrm{NAD}^{+}+\mathrm{H}_{2} \mathrm{O}$, the oxidases perform dehydrogenation of the substrate $\left(\mathrm{SH}_{2}\right)$ by catalyzing the reaction $\mathrm{SH}_{2}+\mathrm{O}_{2} \rightarrow \mathrm{S}+\mathrm{H}_{2} \mathrm{O}_{2}$. Given the significance of oxidation reactions in organic syntheses, the artificial biomimetic flavin-based catalysts have been extensively used to oxidize organic compounds by atmospheric oxygen under mild reaction conditions. ${ }^{7}$ In the case of oxidase-mimicking catalysts, the oxidative power of the flavin is generally enhanced by photoexcitation. This photo-organocatalytic approach facilitates the oxidation of a number of substrates that cannot be oxidized thermally, and has been applied towards the oxidation of aromatic alcohols, amines and other substrates. ${ }^{8-15}$

\footnotetext{
Previous mechanistic studies of the photocatalytic oxidations of benzyl alcohols indicate that the first step involves a photoinduced electron transfer from benzyl alcohol to the excited flavin, followed by the proton and hydrogen-atom transfers to generate the oxidized benzylaldehyde product and the reduced flavin $\mathrm{FlH}_{2} \cdot{ }^{16,17}$ The subsequent regeneration of the catalyst is achieved by a reaction of $\mathrm{FlH}_{2}$ with molecular oxygen via the flavin hydroperoxide (FlHOOH)
} 
intermediate. ${ }^{18-20}$ The initial photoinduced electron transfer from benzyl alcohol can occur to either singlet $\left(\mathrm{S}_{1}\right)$ or triplet $\left(\mathrm{T}_{1}\right)$ excited states of the flavin. However, a recent study by Riedle and coworkers ${ }^{17}$ reported that the electron transfer to the $\mathrm{S}_{1}$ state is not catalytically productive, as it leads to a fast $(\sim 50 \mathrm{ps})$ back electron transfer. On the other hand, electron transfer to the $\mathrm{T}_{1}$ state generates long-lived radical ions $(\sim 5 \mu \mathrm{s})$ that undergo further proton/hydrogen-atom transfers to generate the desired product. Heavy element substituents, such as iodine, are known to increase the $\mathrm{S} \rightarrow \mathrm{T}$ intersystem crossing (ISC) rates in organic compounds due to spin-orbit coupling. ${ }^{21}$ Given the significance of triplet excited states in flavin-based photocatalysis, the aim of this study was to utilize the heavy-atom effect to increase the quantum yield for the $T_{1}$ state formation in flavins. Specifically, it will be shown that the incorporation of the iodine into the flavin framework (I-Fl) leads to a significant increase in the ISC rate relative to the reference compound (Fl, Scheme 1). Furthermore, this manuscript demonstrates that the increased yield of triplet formation in I-Fl directly translates into improved photo-organocatalytic performance relative to the reference model compound. For this purpose, the flavin-catalyzed oxidation of benzyl alcohol to benzaldehyde was used as a model reaction (Scheme 1).

Scheme 1. General Mechanism for Organocatalytic Photooxidation of Benzyl Alcohol by Flavins.

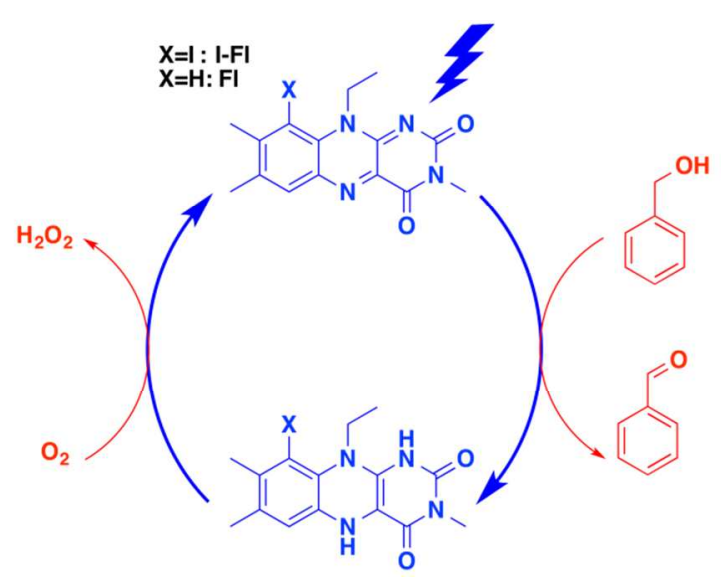




\section{Materials and Methods}

Unless specified, all reagents, starting materials and solvents (HPLC grade) were purchased from commercial sources and used as received without purification. ${ }^{1} \mathrm{H}$ and ${ }^{13} \mathrm{C}$ spectra were recorded at ambient temperature on Bruker Avance $300 \mathrm{MHz}$ NMR or Bruker AVANCEIII $500 \mathrm{MHz}$ NMR spectrometers. Spectra were described as chemical shifts (ppm), multiplicity (s, singlet; d, doublet; t, triplet; q, quartet; m, multiplet), coupling constant in hertz (Hz), and number of protons. All reactions were monitored using silica gel $60 \mathrm{~F}_{254}$ analytical TLC plates with UV detection $(\lambda=254 \mathrm{~nm}$ and $365 \mathrm{~nm})$. Silica gel $(60 \AA, 40-63 \mu \mathrm{m})$ was used as stationary phase for column chromatography.

Synthesis. The isoalloxazine structures of model flavins were synthesized using a condensation between the alloxan and the corresponding aromatic ortho-bis-amine (synthesis of Fl was reported previously). ${ }^{22,23}$ The synthesis of I-Fl was performed using the steps presented in Scheme 2.

Scheme 2. Synthesis of I-Fl.

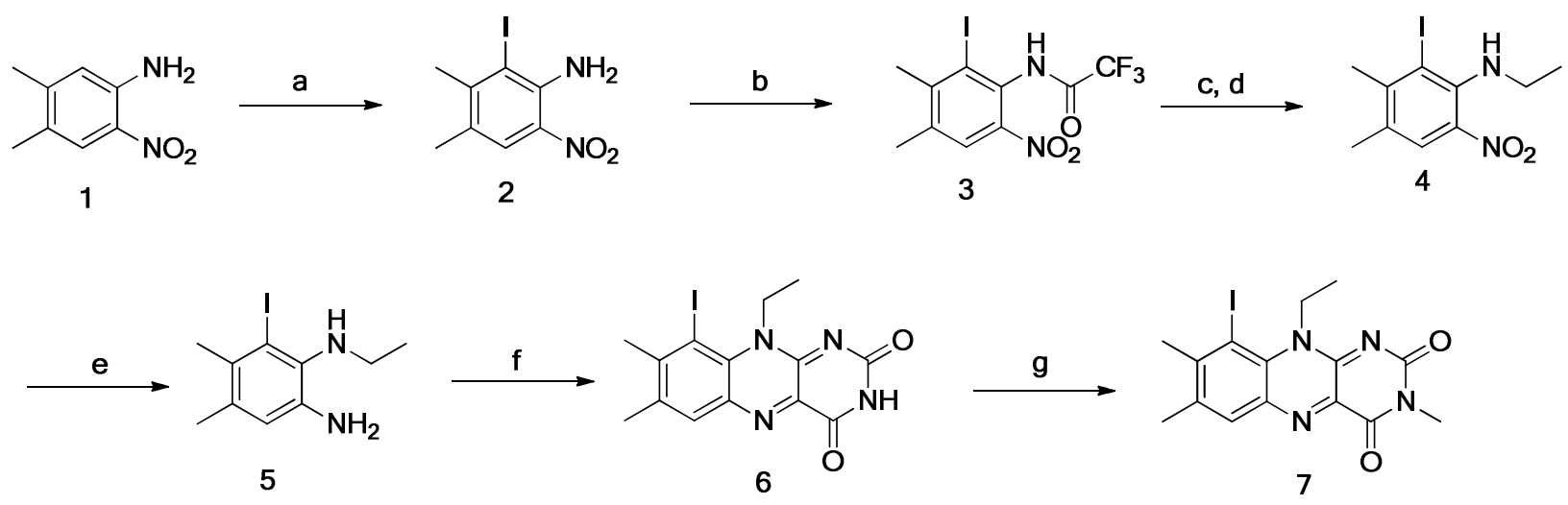

a) $\mathrm{KBrO}_{3}, \mathrm{KI}, \mathrm{HCl}, \mathrm{MeOH} / \mathrm{H}_{2} \mathrm{O}, 60^{\circ} \mathrm{C}, 4 \mathrm{~h}, 92 \%$; b) TFAA, $\mathrm{Et}_{3} \mathrm{~N}, \mathrm{DCM}, 4 \mathrm{~h}, 82 \%$; c) Etl, $\mathrm{K}_{2} \mathrm{CO}_{3}, \mathrm{DMF}, 60^{\circ} \mathrm{C}, 26 \mathrm{~h}$; d) $\mathrm{NaOH}, \mathrm{MeOH} / \mathrm{H}_{2} \mathrm{O}, 65^{\circ} \mathrm{C}, 3 \mathrm{~h}, 76 \%$; e) $\mathrm{Sn}, \mathrm{HCl}, 95^{\circ} \mathrm{C}, 2 \mathrm{~h}, 32 \%$; f) aloxane monohydrate, $\mathrm{B}(\mathrm{OH})_{3}, \mathrm{AcOH}, 10 \mathrm{~h} 67 \%$; g) Mel, $\mathrm{K}_{2} \mathrm{CO}_{3}$, DMF, $72 \mathrm{~h}, 87 \%$ 
6-iodo-4,5-dimethyl-2-nitroaniline (2) - A solution of compound 1 (15 g, 90 mmol), potassium bromate (12 g, $90 \mathrm{mmol})$ and potassium iodide $(15 \mathrm{~g}, 90 \mathrm{mmol})$ was prepared in $450 \mathrm{ml}$ of methanol/water $(2: 3, \mathrm{~V}: \mathrm{V})$ mixture. To the resulting solution concentrated hydrochloric acid ( $37.5 \mathrm{ml}, 450 \mathrm{mmol}$ ) was added and the mixture was heated at $60^{\circ} \mathrm{C}$ for $4 \mathrm{~h}$. The crude product was extracted with dichloromethane $(3 \times 100 \mathrm{ml})$, organic layer was washed with water, 5\% sodium thiosulfate, brine and dried over sodium sulfate. The solvent was removed under reduced pressure and the residue was recrystallized from hexane to give $24 \mathrm{~g}$ (83 mmol, 80\%) of 6-iodo4,5-dimethyl-2-nitroaniline as an orange solid. GCMS: m/z found 292 [291.97 calculated for $\mathrm{C}_{8} \mathrm{H}_{9} \mathrm{IN}_{2} \mathrm{O}_{2}$ ]. ${ }^{1} \mathrm{H}$ NMR (500 MHz, $\left.\mathrm{CD}_{3} \mathrm{CN}\right) \delta$ ppm: 7.95 (s, 1H), 6.74 (s, 2H), 2.43 (s, 3H), 2.30 (s, 3H). 13C NMR (500MHz, $\left.\mathrm{CD}_{3} \mathrm{CN}\right) \delta$ ppm: 146.10, 141.12, 130.34, 125, 54, 124.70, 114.24, $20.63,19.44$.

6-iodo- $N$-(4,5-dimethyl-2-nitrophenyl)-2,2,2-trifluoro-acetamide (3) - Compound 2 (24 g, 83 mmol) was dissolved in $250 \mathrm{ml}$ of dichloromethane. Triethylamine $(9.2 \mathrm{ml}, 6.7 \mathrm{~g}, 165 \mathrm{mmol})$ and trifluoroacetic anhydride $(18.5 \mathrm{ml}, 28 \mathrm{~g}, 133 \mathrm{mmol})$ were added to the reaction mixture and stirred for $4 \mathrm{~h}$. Solution was transferred to a separatory funnel and washed once with $150 \mathrm{ml}$ of 2 $\mathrm{M}$ hydrochloric acid, three times with $100 \mathrm{ml}$ portions of $2 \mathrm{M}$ sodium bicarbonate and once with brine. The organic fraction was dried over anhydrous calcium chloride and the excess solvent was evaporated. The product was purified using flash chromatography (hexane:ethylacetate $=6: 1$ ) to give $28 \mathrm{~g}(72 \mathrm{mmol}, 87 \%)$ of pure compound $\mathbf{3}$ as a white solid. GCMS: $\mathrm{m} / \mathrm{z}$ found 388 [387.95 calculated for $\mathrm{C}_{10} \mathrm{H}_{8} \mathrm{~F}_{3} \mathrm{IN}_{2} \mathrm{O}_{3}$ ]. ${ }^{1} \mathrm{H}$ NMR (500 MHz, $\left.\mathrm{CD}_{3} \mathrm{CN}\right) \delta$ ppm: $9.38(\mathrm{~s}, 1 \mathrm{H}), 7.89$ $(\mathrm{s}, 1 \mathrm{H}), 2,50(\mathrm{~s}, 3 \mathrm{H}), 2.45(\mathrm{~s}, 3 \mathrm{H}) .{ }^{13} \mathrm{C} \mathrm{NMR}\left(500 \mathrm{MHz}, \mathrm{CD}_{3} \mathrm{CN}\right) \delta \mathrm{ppm}: 156.7\left(\mathrm{q}, \mathrm{J}^{\mathrm{C}-\mathrm{F}}=155\right.$ Hz), 145.79, 141.30, 127.67, 125.98, 125.12, 21.35, 21.33. 
6-iodo- $N$-ethyl- $N$-(4,5-dimethyl-2-nitro-phenyl)-amine (4) - Compound 3 (27 g, 70 mmol) was dissolved in $150 \mathrm{ml}$ of DMF, anhydrous potassium carbonate $(19 \mathrm{~g}, 140 \mathrm{mmol})$ and $3.2 \mathrm{ml}$ of ethyl iodide $(15 \mathrm{~mL}, 30 \mathrm{~g}, 190 \mathrm{mmol})$ were added and the mixture was stirred for $26 \mathrm{~h}$ at $60^{\circ}$ C. Once the conversion was completed, $100 \mathrm{ml}$ of $10 \%$ solution of $\mathrm{NaOH}$ in methanol:water (1:1) was added. The mixture was heated at $65^{\circ} \mathrm{C}$ for $3 \mathrm{~h}$, cooled to $\mathrm{rt}$, extracted with dichloromethane, the organic layer was dried over calcium chloride and the solvent was evaporated under reduced pressure. The crude product was purified by flash chromatography (hexane:ethyl acetate, 10:1) to give $16 \mathrm{~g}(50 \mathrm{mmol}, 72 \%)$ of compound 4 as a bright orange oil, which crystallized upon cooling. GCMS: m/z found 320 [320.00 calculated for $\left.\mathrm{C}_{10} \mathrm{H}_{13} \mathrm{IN}_{2} \mathrm{O}_{2}\right] .{ }^{1} \mathrm{H}$ NMR (500 MHz, CD 3 CN) $\delta$ ppm: 7.67 (s, 1H), 5.54 (s, 1H), 3.13 (q, J=10 Hz, 2H), 2.41 (s, 3H), $2.29(\mathrm{~s}, 3 \mathrm{H}), 1.15(\mathrm{t}, \mathrm{J}=10 \mathrm{~Hz}, 3 \mathrm{H}) .{ }^{13} \mathrm{C} \mathrm{NMR}\left(500 \mathrm{MHz}, \mathrm{CD}_{3} \mathrm{CN}\right) \delta \mathrm{ppm}: 145.41,141.78$, $129.57,126.12,119.67,43.45,21.59,20.53,16.09$.

6-iodo- $N$-ethyl-4,5-dimethyl-benzene-1,2-diamine (5) - Compound 4 (15 g, 47 mmol) was partially dissolved in $250 \mathrm{ml}$ of $12 \mathrm{M} \mathrm{HCl}$. The reaction mixture was heated to $95^{\circ} \mathrm{C}$ and tin foil (27 $\mathrm{g}, 230 \mathrm{mmol})$ in small amounts was added to the reaction mixture until solution became colorless. The reaction mixture was cooled down and $6 \mathrm{M} \mathrm{NaOH}$ was added drop wise until the $\mathrm{pH}$ of the mixture became 10. The formed suspension was heated and passed through a bed of celite. The filtrate was extracted with dichloromethane, the organic layer was dried over sodium sulfate and evaporated under reduced pressure. Crude product was purified using column chromatography (ethyl acetate:hexane 1:9) to give $4.13 \mathrm{~g}(15 \mathrm{mmol}, 32 \%)$ of compound 5 as a brown oil. CGMS: m/z found 290 [290.03 calculated for $\left[\mathrm{C}_{10} \mathrm{H}_{15} \mathrm{IN}_{2}\right] .{ }^{1} \mathrm{H} \mathrm{NMR}(500 \mathrm{MHz}$, $\left.\mathrm{CD}_{3} \mathrm{CN}\right) \delta$ ppm: $6.50(\mathrm{~s}, 1 \mathrm{H}), 4.10(\mathrm{~s}, 2 \mathrm{H}), 3.25(\mathrm{~s}, 1 \mathrm{H}), 2.85$ (q, J=5 Hz, 2H), 2.23 (s, 3H), 2.17 
$(\mathrm{s}, 3 \mathrm{H}), 1.15(\mathrm{t}, \mathrm{J}=7.5,3 \mathrm{H}) .{ }^{13} \mathrm{C} \mathrm{NMR}\left(500 \mathrm{MHz}, \mathrm{CD}_{3} \mathrm{CN}\right) \delta \mathrm{ppm}: 141.83,133.93,131.97$, $125.12,124.27,116.68,42.27,21.01,19.65,16.06$.

10-ethyl-9-iodo-7,8-dimethylbenzo[g]pteridine-2,4(3H,10H)-dione (6) - Compound 5 (3.5 g, $12.7 \mathrm{mmol})$ was added drop wise to the suspension of alloxan monohydrate $(4.1 \mathrm{~g}, 25.4 \mathrm{mmol})$ and boric acid $(0.4 \mathrm{~g}, 6.4 \mathrm{mmol})$ in $20 \mathrm{ml}$ of glacial acetic acid. The mixture was stirred overnight and the precipitate was filtered off and recrystallized from methanol to give $3.4 \mathrm{~g}$ (8.5 mmol, 67\%) of compound 6 as a yellow solid. MALDI MS, m/z found: 396 [396.01 calculated for $\mathrm{C}_{14} \mathrm{H}_{13} \mathrm{IN}_{4} \mathrm{O}_{2}$ ]. ${ }^{1} \mathrm{H}$ NMR (500 MHz, DMSO-d6) $\delta$ ppm: 11.44 (s, 1H), 7.92 (s, 1H), 4.82 (q, $\mathrm{J}=7.5,2 \mathrm{H}), 2.60(\mathrm{~s}, 3 \mathrm{H}), 2.49(\mathrm{~s}, 3 \mathrm{H}), 1.55(\mathrm{t}, \mathrm{J}=7.5,3 \mathrm{H}) .{ }^{13} \mathrm{C}$ NMR (500 MHz, DMSO-d6) $\delta$ ppm: 159.61, 155.64, 152.78, 146.76, 138.09, 136.13, 135.39, 131.59, 131.49, 110.82, 45.76, $22.38,20.71,14.55$.

I-Fl (10-ethyl-9-iodo-3,7,8-trimethylbenzo[g]pteridine-2,4(3H,10H)-dione) (7) - Compound $6(3 \mathrm{~g}, 7.6 \mathrm{mmol})$ was partially dissolved in $50 \mathrm{ml}$ of dry DMF, then $\mathrm{K}_{2} \mathrm{CO}_{3}(5.3 \mathrm{~g}, 38 \mathrm{mmol})$ and iodomethane $(2.4 \mathrm{ml}, 5.4 \mathrm{~g}, 38 \mathrm{mmol})$ were added. The mixture was stirred at room temperature for three days. Brine $(\sim 100 \mathrm{ml})$ was added to the solution and the mixture was extracted with dichloromethane. Crude product was purified by flash chromatography (acetone:DCM - 1:2) to give $2.6 \mathrm{~g}(6.3 \mathrm{mmol}, 83 \%)$ of $\mathrm{I}-\mathrm{Fl}$ as an orange solid. MALDI MS, $\mathrm{m} / \mathrm{z}$ found: 410.14 [410.02 calculated for $\mathrm{C}_{15} \mathrm{H}_{15} \mathrm{IN}_{4} \mathrm{O}_{2}$ ]. ${ }^{1} \mathrm{H}$ NMR (500 MHz, DMSO-d6) $\delta$ ppm: 7.99 $(\mathrm{s}, 1 \mathrm{H}), 4.87$ (q, J=7.5, 2H), $3.27(\mathrm{~s}, 3 \mathrm{H}), 2.61(\mathrm{~s}, 3 \mathrm{H}), 1.55(\mathrm{t}, \mathrm{J}=7.5,3 \mathrm{H}) .{ }^{13} \mathrm{C} \mathrm{NMR}(500 \mathrm{MHz}$, DMSO-d6) $\delta$ ppm: 159.85, 155.62, 151.72, 147.41, 137.68, 136.69, 136.03, 132.02, 131.89, $111.20,45.92,28.36,22.86,21.16,15.01$.

Femtosecond Transient Absorption (fs TA) Experiments. The laser system for the fs TA measurements was described previously. ${ }^{24}$ Briefly, the $800 \mathrm{~nm}$ laser pulses were produced at a 1 
$\mathrm{kHz}$ repetition rate (fwhm $=110 \mathrm{fs}$ ) by a mode-locked Ti:sapphire laser (Hurricane, SpectraPhysics). The output from the Hurricane was split into pump (85\%) and probe (10\%) beams. The pump beam $(800 \mathrm{~nm})$ was sent into an optical parametric amplifier (OPA-400, Spectra Physics) to obtain the $480 \mathrm{~nm}$ pump pulses $(\mathrm{E}<1 \mu \mathrm{J} / \mathrm{pulse})$. The probe beam was focused into a horizontally moving $\mathrm{CaF}_{2}$ crystal for white light continuum generation between 350 and $800 \mathrm{~nm}$. The relative polarization between the pump and the probe beams was set at the magic angle $\left(54.7^{\circ}\right)$. The pump and probe beams were overlapped in the sample. The flow cell (Starna Cell Inc. 45-Q-2, $0.9 \mathrm{~mL}$ volume with $2 \mathrm{~mm}$ path length), pumped by a Fluid Metering RHSY Lab pump (Scientific Support Inc.), was used to prevent photodegradation of the sample. After passing through the cell, the continuum was coupled into an optical fiber and input into a CCD spectrograph (Ocean Optics, S2000). The data acquisition was achieved using in-house LabVIEW (National Instruments) software routines. The group velocity dispersion of the probing pulse was determined using nonresonant optical Kerr effect (OKE) measurements. Sample solutions were prepared at a concentration needed to have absorbance of A 0.6-1.0 at the excitation wavelength.

Nanosecond Transient Absorption (ns TA) Experiments. The nanosecond laser flash photolysis experimental setup utilized for the measurements in this paper is described in detail elsewhere. ${ }^{25}$ Briefly, a Nd:YAG laser (Spectra Physics LAB-150-10) was used as the excitation light source with an excitation wavelength of $355 \mathrm{~nm}$. The probe light was supplied by a $150 \mathrm{~W}$ xenon arc lamp (Applied Photophysics) used in pulsed mode $(0.5 \mathrm{~ms}$ in duration) with a $1 \mathrm{~Hz}$ repetition rate. Transient absorption spectra were recorded using a Roper ICCD-Max 512T digital intensified CCD camera with up to 2 ns temporal resolution. The single wavelength kinetic measurements were recorded using a PMT connected to an oscilloscope (Tektronix TDS 
680C $5 \mathrm{Gs} / \mathrm{s} 1 \mathrm{GHz}$ ), which was connected to a computer that runs a custom LabView control and acquisition program. Sample solutions were prepared at a concentration needed to have absorbance of A 0.5-0.8 at the excitation wavelength $(355 \mathrm{~nm})$. Solutions were placed in a quartz cuvette and deoxygenated prior to ns TA experiments by purging with argon.

Photocatalysis. A $10 \mathrm{ml}$ vial was charged with the catalyst $(1-10 \mathrm{~mol} \%)$, thiourea $(15 \mathrm{~mol} \%$, if needed) and $3 \mathrm{ml}$ of solvent. The resulting mixture was stirred in the dark until all reagents dissolved. Then $\mathrm{BnOH}$ (1 eq.) was added and the vial was placed under $12 \mathrm{~W}$ LED lamp ( $\lambda=440$ $\mathrm{nm})$. Reaction mixture was stirred for the required time while being monitored by TLC and ${ }^{1} \mathrm{H}$ NMR methods. The supporting information contains the representative NMR spectra (Figures S1 and S2).

Example (Table 1. Entry 13): A $10 \mathrm{ml}$ vial was charged with I-F1 (11 mg, $27 \mu \mathrm{mol})$, thiourea (31 $\mathrm{mg}, 0.41 \mathrm{mmol}$ ) and $3 \mathrm{ml}$ of 5\% DMSO-d6 in ACN-d3. The mixture was stirred in the dark for 5 min. Then $\mathrm{BnOH}(292 \mathrm{mg}, 0.28 \mathrm{ml}, 2.7 \mathrm{mmol}$ ) was added and the vial was placed under $12 \mathrm{~W}$ LED lamp $(\lambda=440 \mathrm{~nm})$. Reaction mixture was stirred for $5 \mathrm{~h}$ until full conversion of the starting alcohol has been detected. $50 \mu \mathrm{l}$ of the mixture was diluted up to $0.5 \mathrm{ml}$ and analyzed by ${ }^{1} \mathrm{H}$ NMR to show $98 \%$ yield of benzaldehyde (1,3,5-trimethoxybenzene as a standard).

Photostability test. Oven dried vial was charged with solution of $\mathrm{BnOH}$ in 5\% DMSO-d6 in CD3CN $\left(4.7 \times 10^{-3} \mathrm{M}, 3 \mathrm{~mL}\right)$, standard, magnetic stirrer bar and thiourea (15 mol\%). Then, the catalyst $(10 \mathrm{~mol} \%)$ was added and the mixture was stirred in the dark until all reagents were dissolved. The vial was placed under LED (440 nm, 12W) and the mixture was stirred under light. Reactions were monitored by TLC. Once reaction was complete (155 minutes for Fl and 90 minutes for I-Fl), the product yield was determined using NMR $(1,3,5$ trimethoxybenzene was used as an internal standard). Then, another portion of neat alcohol was added to the mixture and 
the procedure was repeated for additional cycle. For every additional cycle, the amount of $\mathrm{BnOH}$ to be added was calculated based on NMR yields to match the initial concentration of $4.7 \mathrm{mmol}$.

\section{Results and Discussions}

The UV/Vis absorption spectra of Fl and I-Fl (Figure 1a) are similar, with two absorption bands at approximately 350 and $450 \mathrm{~nm}$ arising due to $\pi, \pi^{*}$ electronic transitions. ${ }^{22}$ The spectral similarity indicates that Fl and I-Fl have almost equal capacity to drive useful photochemical transformations using the energy of blue photons. The standard reduction potentials for Fl and IF1 were obtained using cyclic voltammetry (Figure 1b). Both model compounds exhibit two reduction peaks associated with the formation of the semiquinone and hydroquinone forms of the flavin. $^{22}$ The I-Fl reduces at a more positive potential, indicating that it is a better electron acceptor. Assuming that the triplet excited state energies of Fl and I-Fl are the same, this implies that the driving force for the photoinduced electron transfer from $\mathrm{T}_{1}$ state of I-Fl to the substrate is by $0.15 \mathrm{eV}$ larger than the corresponding driving force for $\mathrm{Fl}$. 

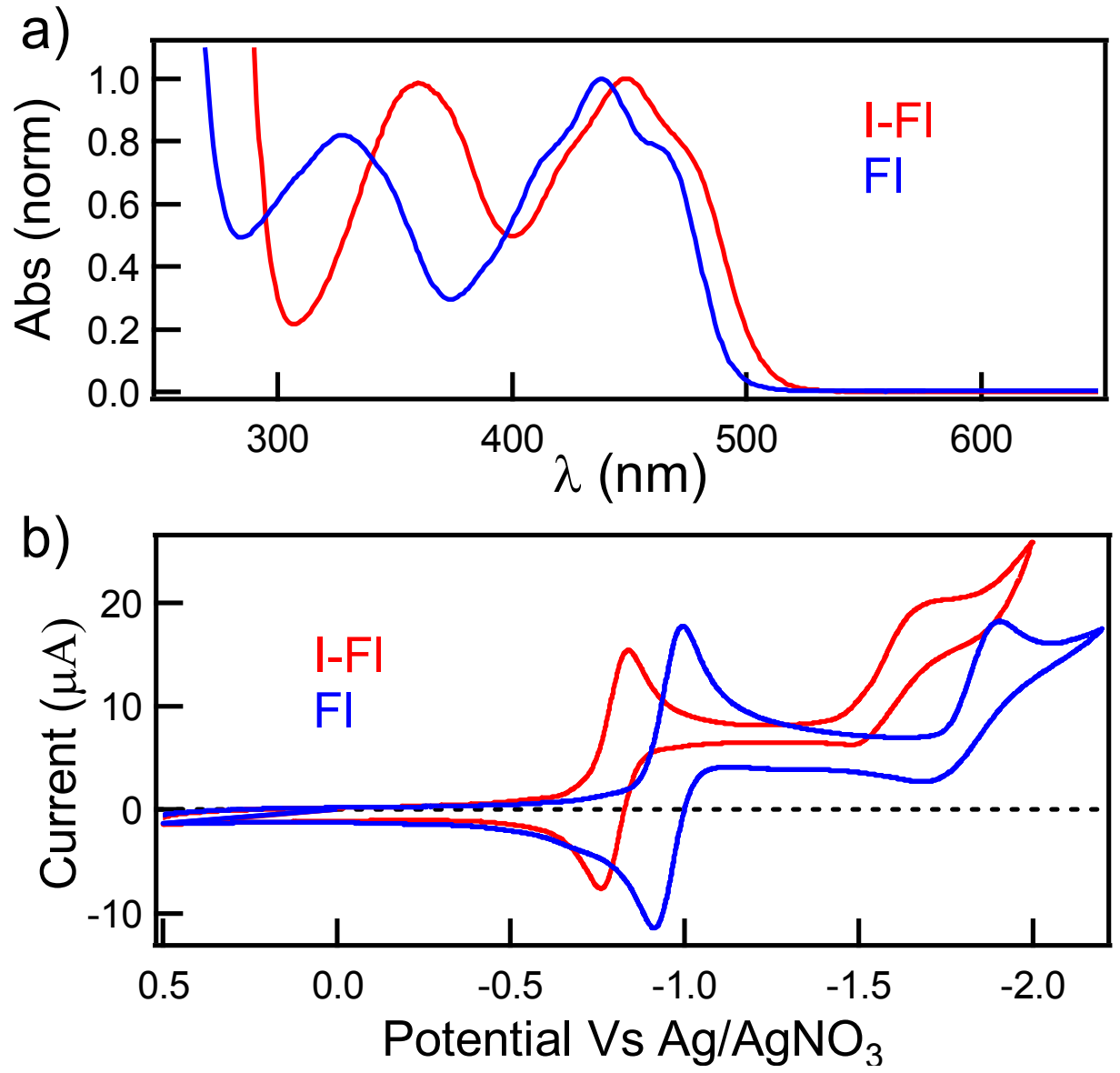

Figure 1. a) Absorption spectra of Fl (blue) and I-Fl (red) in acetonitrile; (b) cyclic voltammograms of Fl (blue) and I-Fl (red) in 0.1 M TBAP in acetonitrile (Pt working electrode, $0.1 \mathrm{~V} / \mathrm{s}$ scan rate). The first reduction potentials are at $-0.95 \mathrm{~V}(\mathrm{Fl})$ at $-0.85 \mathrm{~V}$ (I-Fl) vs. $\mathrm{Ag} / \mathrm{AgNO}_{3}$

Femtosecond pump-probe experiments were performed to evaluate the ISC rates in model flavins. The transient spectra collected at early times are assigned to the ${ }^{1} \pi, \pi^{*}$ states of Fl and IF1 (Figure 2a), and consist of the ground state bleach $(400-500 \mathrm{~nm})$, stimulated emission (500$700 \mathrm{~nm})$ and excited-state absorption $(350-400 \mathrm{~nm}$ and $\sim 500 \mathrm{~nm})$ bands. The lifetimes of these ${ }^{1} \pi, \pi^{*}$ states are significantly different in the two model compounds: in the case of $\mathrm{Fl}$, the ${ }^{1} \pi, \pi^{*}$ 
state decays within several nanoseconds to form the ${ }^{3} \pi, \pi^{*}$ state, ${ }^{22}$ while the spin inversion occurs with a lifetime of only 87 ps for I-Fl (Figure $2 b$ ). The formation of the ${ }^{3} \pi, \pi^{*}$ state of I-Fl is observed as growths of absorption bands at $400 \mathrm{~nm}$ and in the 500-700 $\mathrm{nm}$ range. The significantly faster ISC rate and the absence of ground state bleach recovery in the case of I-Fl demonstrates that the incorporation of iodine provides an efficient route towards increased triplet state quantum yields in flavin derivatives.
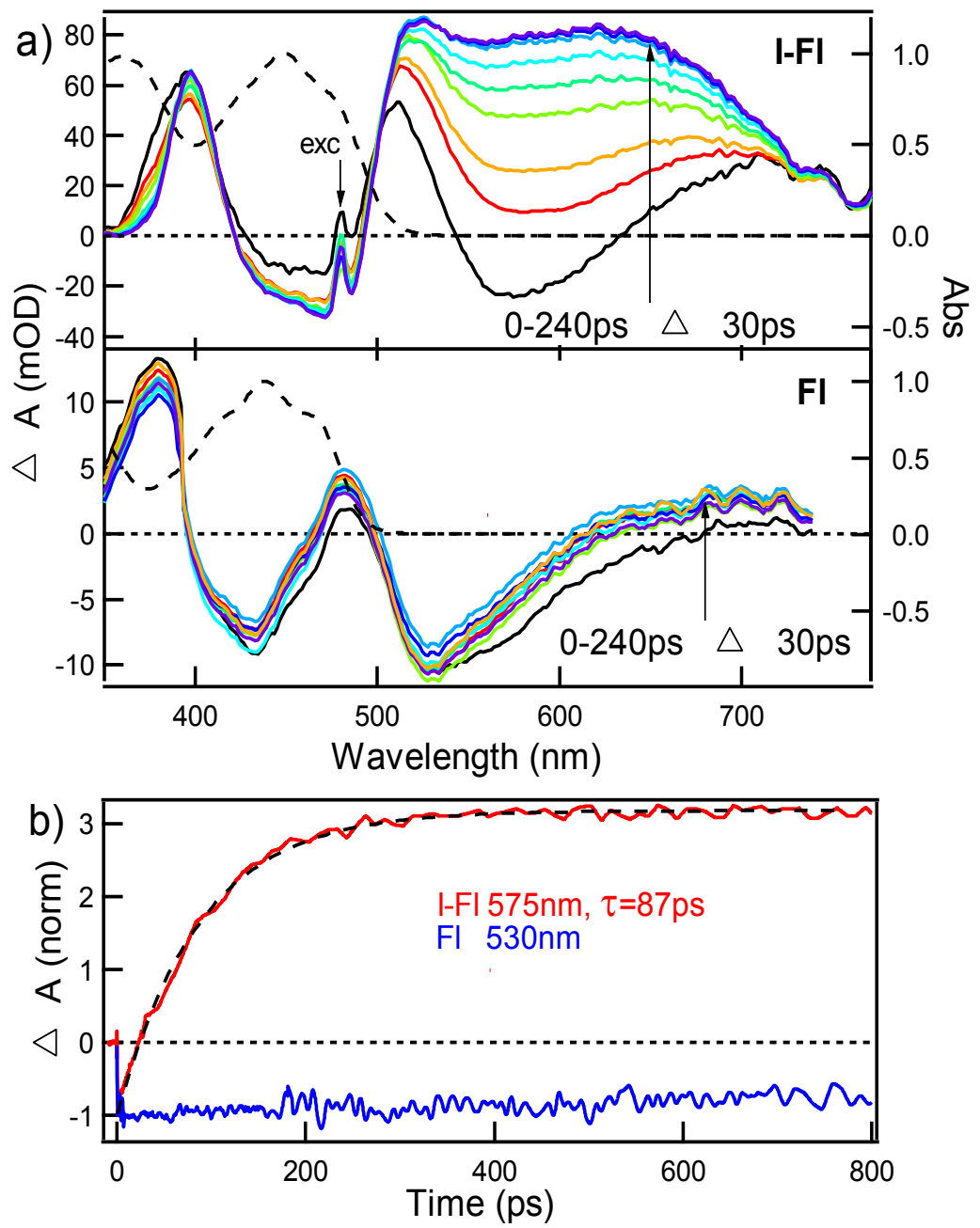

Figure 2. (a) Transient absorption difference spectra of I-Fl (upper panel) and Fl (lower panel) in acetonitrile (ACN) collected 0-240 ps after the $480 \mathrm{~nm}$ excitation pulse. The ground state absorption spectra of Fl and I-Fl are presented as dashed curves for comparison; (b) Kinetic 
profiles for I-Fl, probed at $575 \mathrm{~nm}$ (red) with exponential fit (dashed), and Fl, probed at $530 \mathrm{~nm}$ (blue).

The lifetimes of the triplet excited states in Fl and I-Fl were evaluated using nanosecond transient absorption spectroscopy (Figure 3 ). The ${ }^{3} \pi, \pi^{*}$ states of Fl and I-Fl exhibit broad absorption features that cover the entire visible range (Figure 3a). Both triplets decay on the microsecond timescale, as can be observed from the kinetic traces probed at $600 \mathrm{~nm}$ (Figure 3b). The triplet excited lifetime of I-Fl is somewhat shorter $(5.8 \mu \mathrm{s})$ than the lifetime of the corresponding triplet in Fl $(12.6 \mu \mathrm{s})$. Even though the kinetic traces obtained in Figure $3 \mathrm{~b}$ were obtained using the lowest possible power of the pump beam, it is possible that the lifetimes are affected by the bimolecular annihilation processes. ${ }^{26}$ The shortening of the triplet excited-state lifetime in I-Fl is consistent with the heavy atom effect caused by the iodo-substituent: the spinorbit interaction in I-Fl causes not only an increase in the rate of $S_{1} \rightarrow T_{1}$ intersystem crossing (Figure $2 \mathrm{~b}$ ), but also leads to increased rate of the $\mathrm{T}_{1} \rightarrow \mathrm{S}_{0}$ relaxation pathway (Figure $3 \mathrm{~b}$ ). Importantly, this heavy-atom effect is much more pronounced in accelerating the $S_{1} \rightarrow T_{1}$ process (ISC rate in I-Fl is $\sim 100$ times higher than in Fl, Figure $2 \mathrm{~b}$ ) than in accelerating the $\mathrm{T}_{1} \rightarrow \mathrm{S}_{0}$ relaxation (rate is only $\sim 2$ times faster, Figure $3 b$ ). Such situation is ideal for promoting the photocatalytic processes using triplet excited state of flavin, where one needs high triplet quantum yields (which is assured with fast ISC rates) and long triplet excited-state lifetimes, thus providing sufficient time for the photochemical event to take place. 

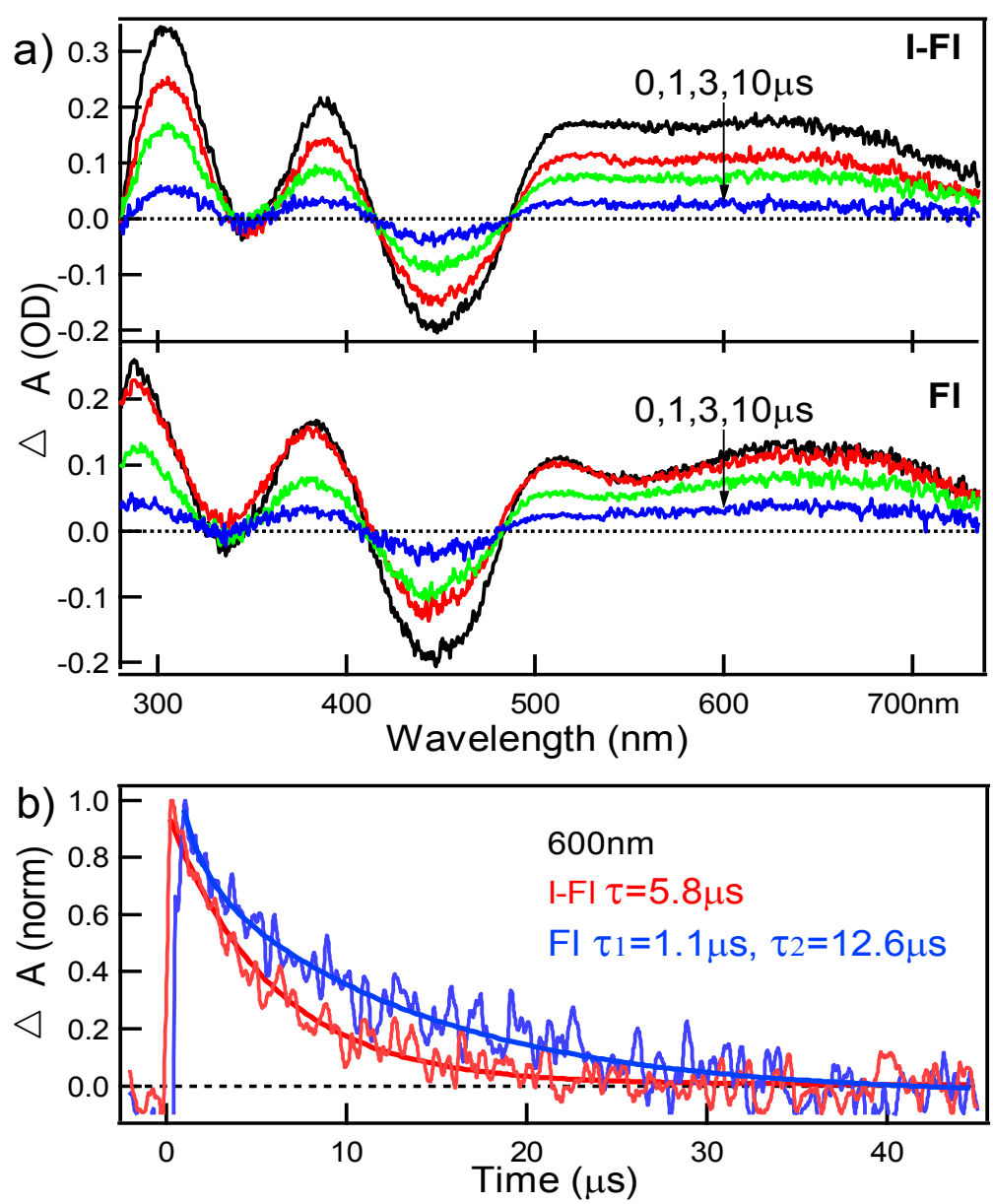

Figure 3. (a) Transient absorption difference spectra of I-Fl (upper panel) and Fl (lower panel) in acetonitrile (ACN) collected from 0 to $10 \mu$ s after the $355 \mathrm{~nm}$ excitation pulse; (b) Kinetic profiles for I-Fl (red) and Fl (blue) probed at $600 \mathrm{~nm}$.

The photocatalytic efficiency of I-Fl was evaluated using the oxidation of benzyl alcohol as a model reaction (Scheme 3). The catalysis was evaluated in three solvent mixtures: DMSO/ACN, DMSO $/ \mathrm{H}_{2} \mathrm{O}$ and $\mathrm{ACN} / \mathrm{H}_{2} \mathrm{O}$ (Table 1). The product yields were highest in the $\mathrm{ACN} / \mathrm{H}_{2} \mathrm{O}$ solvent mixture (for example, compare entries 2, 4 and 6), which is consistent with the previous reports showing that the higher polarity solvents more efficiently stabilize the radical ions formed after the photoinduced electron transfer. ${ }^{16}$ The addition of thiourea as an electron mediator ${ }^{10}$ 
significantly increases the benzaldehyde yield (for example, compare entries 2 and 8 ). In addition, the $10 \mathrm{~mol} \%$ catalyst loading gives higher benzaldehyde yields (entry 8) than the 1 mol\% loading (entry 11). Importantly, the comparison of Fl and I-Fl photocatalysis revealed that I-Fl provided consistently higher benzaldehyde yields. For example, entries 7 and 8 report two reactions in which all experimental conditions were identical, except that different catalysts were used. While the I-Fl catalyst provided a 100\% yield of benzaldehyde, the yield in the presence of Fl was only $72 \%$. These results are consistent with the previous report ${ }^{17}$ showing that the efficient catalysis occurs from the triplet excited-state of flavin, while the singlet excited state leads to undesired charge recombination process. Since the iodine in I-Fl provides higher triplet quantum yield and lower singlet excited-state lifetime, the photocatalysis is more efficient for IF1.

Scheme 3. Organocatalytic photooxidation of benzyl alcohol.

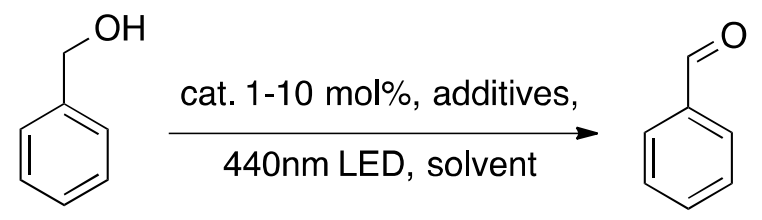

Table 1. Catalytic Photooxidation with Flavins.

\begin{tabular}{lcccc}
\hline Entry & $\begin{array}{c}\text { Catalyst, } \\
(\mathrm{mol} \%)\end{array}$ & Solvent & $\begin{array}{c}\text { Time, } \\
\mathrm{h}\end{array}$ & $\begin{array}{c}\text { Yield, } \\
\%\end{array}$ \\
\hline 1 & $\mathrm{Fl}(10)$ & $\begin{array}{l}\text { 5\% DMSO } \\
\text { in ACN }\end{array}$ & 1.5 & 31 \\
2 & I-Fl (10) & $\begin{array}{l}5 \% \mathrm{DMSO} \\
\text { in ACN }\end{array}$ & 1.5 & 42 \\
3 & Fl (10) & $5 \%$ DMSO & 1.5 & 41
\end{tabular}


in $\mathrm{H} 2 \mathrm{O}$

\begin{tabular}{|c|c|c|c|c|}
\hline 4 & I-Fl (10) & $\begin{array}{l}5 \% \text { DMSO } \\
\text { in } \mathrm{H} 2 \mathrm{O}\end{array}$ & 1.5 & 54 \\
\hline 5 & Fl (10) & $\begin{array}{l}\text { ACN:H2O } \\
(1: 2)\end{array}$ & 1.5 & 77 \\
\hline 6 & I-Fl (10) & $\begin{array}{l}\text { ACN:H2O } \\
(1: 2)\end{array}$ & 1.5 & 89 \\
\hline $7^{\mathrm{b}}$ & Fl (10) & $\begin{array}{l}5 \% \text { DMSO } \\
\text { in } \mathrm{ACN}\end{array}$ & 1.5 & 72 \\
\hline $8^{b}$ & I-F1 (10) & $\begin{array}{l}5 \% \text { DMSO } \\
\text { in } \mathrm{ACN}\end{array}$ & 1.5 & $>95$ \\
\hline $9^{b}$ & Fl (10) & $\begin{array}{l}5 \% \text { DMSO } \\
\text { in } \mathrm{ACN}\end{array}$ & 2.5 & $>95$ \\
\hline $10^{\mathrm{b}}$ & Fl (1) & $\begin{array}{l}5 \% \text { DMSO } \\
\text { in } \mathrm{ACN}\end{array}$ & 12 & 48 \\
\hline $11^{b}$ & I-Fl (1) & $\begin{array}{l}5 \% \text { DMSO } \\
\text { in } \mathrm{ACN}\end{array}$ & 12 & 54 \\
\hline $12^{b, c}$ & Fl (1) & $\begin{array}{l}5 \% \text { DMSO } \\
\text { in } \mathrm{ACN}\end{array}$ & 5 & 21 \\
\hline $13^{b, c}$ & I-Fl (1) & $\begin{array}{l}5 \% \text { DMSO } \\
\text { in } \mathrm{ACN}\end{array}$ & 5 & $>95$ \\
\hline
\end{tabular}

Conditions: benzyl alcohol $4.5 \times 10^{-3} \mathrm{M}$ a) NMR yields, 1,3,5-trimethoxybenzene as a standard, b) thiourea $15 \mathrm{~mol} \%$, c) $0.9 \mathrm{M}$ of $\mathrm{BnOH}$

Furthermore, the use of I-Fl as a photocatalyst allows the use of higher concentrations of the benzyl-alcohol substrate. To avoid the unwanted charge recombination that occurs from the singlet excited state pathway, the catalysis by flavins is optimal when lower concentrations of 
reactant are used (highest yields were obtained at $25 \mathrm{mM}$ substrate concentration). ${ }^{17}$ Similar behavior was observed in this work: when benzyl alcohol concentration was increased from 4.5 $\mathrm{mM}$ to $0.9 \mathrm{M}$, the product yield in the presence of $\mathrm{Fl}$ as a catalyst decreased from 48 to $21 \%$ (entries 10 and 12). The opposite results were obtained when I-Fl was used as a catalyst (entries 11 and 13), where almost quantitative conversion occurred at $0.9 \mathrm{M}$ substrate concentration. The improved catalytic efficiency of I-Fl at high substrate concentration is expected to facilitate the scale-up of the flavin-based photooxidation reactions.

The photocatalytic performance of I-Fl was compared to that of Fl by evaluating the time it takes to bring the $\mathrm{BnOH}$ oxidation to completion. In the case of $\mathrm{Fl}$, the reaction took 120 minutes, while I-Fl photocatalysis required only 90 minutes under identical experimental conditions (entry 1, Figure 4). There results indicate that the quantum yield for I-Fl catalysis is higher than for Fl, and are consistent with the higher photoreactivity of the triplet excited state. However, subsequent addition of $\mathrm{BnOH}$ to the reaction mixture (entries 2-4, Figure 4) led to a decrease in oxidation yields for both $\mathrm{Fl}$ and I-Fl, indicating that the model flavin catalysts undergo photodecomposition. In the case of I-Fl, the photodecomposition was more pronounced, as evidenced by a more drastic decrease in the product yields. It appears that the triplet excited state in I-Fl is responsible for the unwanted photochemical reaction that causes the catalyst decomposition. 


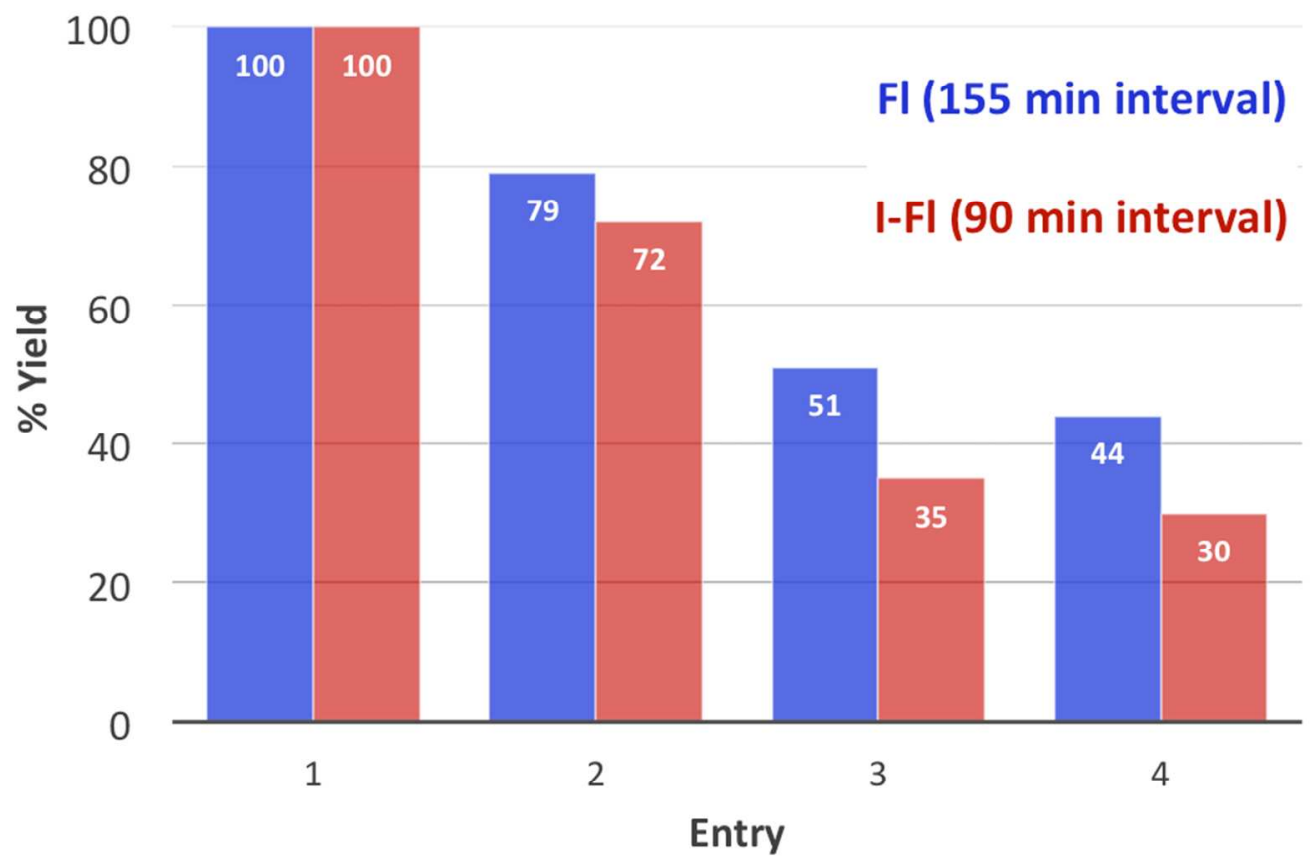

Figure 4. The \% yields of benzaldehyde formed using Fl (blue) or I-Fl (red) as a photocatalyst. The $\mathrm{BnOH}$ oxidation was performed until all alcohol was converted to aldehyde (which took 155 minutes for $\mathrm{Fl}$ and 90 minutes for $\mathrm{I}-\mathrm{Fl}$ ). Then, a new portion of $\mathrm{BnOH}$ was added and the procedure was repeated in the same time interval. The reactions were performed in 5\% DMSOd6 in $\mathrm{CD}_{3} \mathrm{CN}$ and in the presence of $15 \mathrm{~mol} \%$ urea.

To evaluate the energetics for the photoinduced charge transfer from excited Fl and I-Fl, a diagram showing the reduction potentials of excited flavin models is shown in Scheme 4. The reported potentials are only estimates rather than the exact values, because the standard reduction potential of benzyl alcohol radical cation $\left(\mathrm{BnOH}^{+}\right)$is not known (instead, anodic peak potential for $\mathrm{BnOH}$ oxidation was used ${ }^{27}$ ) and because the reduction potentials for the flavin models in their $\mathrm{T}_{1}$ state were obtained under assumption that their triplet energies are the same as that of riboflavin. ${ }^{28}$ Despite these possible sources of error, it appears that the photoinduced electron 
transfer is thermodynamically favorable only for the flavins in their singlet excited state. Surprisingly, the reduction potentials of Fl and I-Fl in their triplet states are significantly below the oxidation potential of $\mathrm{BnOH}$, making it unlikely that the photoinduced electron transfer from $\mathrm{T}_{1}$ states of flavins to $\mathrm{BnOH}$ is taking place. Based on these thermodynamic arguments, we postulate that the photooxidation of $\mathrm{BnOH}$ proceeds by a hydrogen atom transfer mechanism. However, further time-resolved experiments are needed to provide more insights into this process.

E vs NHE

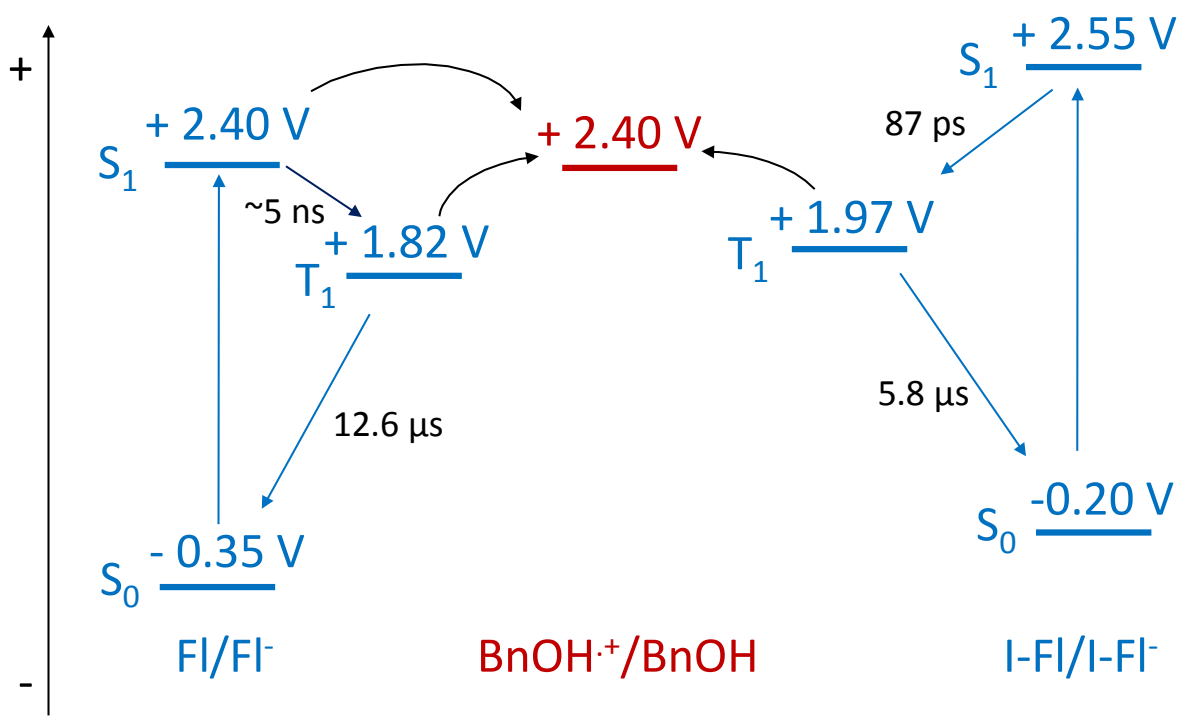

Scheme 4. Diagram showing the standard reduction potentials of relevant species. The standard reduction potentials of $\mathrm{Fl}$ and $\mathrm{I}-\mathrm{Fl}$ in their ground states were obtained from the cyclic voltammograms in Figure 1b. The corresponding potentials in the $\mathrm{S}_{1}$ states were obtained using the energies of the lowest absorption bands shown in Figure 1a. The potentials in the $\mathrm{T}_{1}$ states were obtained assuming the triplet energy of riboflavin $(2.17 \mathrm{eV}) .{ }^{28}$ For the oxidation potential of $\mathrm{BnOH}$, the anodic peak potential value for a chemically irreversible oxidation was used. ${ }^{27}$

\section{Conclusion}


In conclusion, the iodo-substituted flavin was synthesized and shown to exhibit higher rate of triplet formation and improved photocatalytic efficiency. These results verify that the triplet excited-state of flavin plays an important role in photocatalytic oxidations of organic substrates. Our findings are expected to contribute to the current research efforts in the area of photocatalytic organic synthesis. ${ }^{29-31}$ Furthermore, the iodo-flavin analog reported here will likely find applications in biological sciences, as an artificial cofactor for photoactive flavoproteins. $^{32-34}$

\section{ASSOCIATED CONTENT}

\section{Supporting Information.}

The Supporting Information is available free of charge via the Internet at http://pubs.acs.org.

Photocatalysis data.

\section{AUTHOR INFORMATION}

\section{Corresponding Author}

$\underline{* \text { kglusac@,bgsu.edu }}$

The authors declare no competing financial interest.

\section{Funding Sources}

We are grateful to the National Science Foundation (CHE-1055397 to K.D.G. and DMR1212842 to C.M.H.) for funding this work. 


\section{REFERENCES}

(1) Huijbers, M. M. E.; Montersino, S.; Westphal, A. H.; Tischler, D.; van Berkel, W. J. H. Flavin Dependant Monooxygenases. Arch Biochem Biophys 2014, 544, 2.

(2) Mansoorabadi, S. O.; Thibodeaux, C. J.; Liu, H. W. The Diverse Roles of Flavin Coenzymess - Nature’s Most Versatile Thespians. J Org Chem 2007, 72, 6329.

(3) Gadda, G. Hydride Transfer Made Easy in the Reaction of Alcohol Oxidation Catalyzed by Flavin-dependent Oxidases. Biochemistry 2008, 47, 13745.

(4) Schaefer-Ramadan, S.; Gannon, S. A.; Thorpe, C. Human Augmenter of Liver Regeneration: Probing the Catalytic Mechanism of a Flavin-Dependent Sulfhydryl Oxidase. Biochemistry 2013, 52, 8323.

(5) Fagan, R. L.; Palfey, B. A. In Comprehensive Natural Products II; Liu, H.-W., Mander, L., Eds.; Elsevier: Oxford, 2010, p 37.

(6) Cashman, J. R.; Motika, M. S. In Comprehensive Toxicology (Second Edition); McQueen, C. A., Ed.; Elsevier: Oxford, 2010, p 77.

(7) Iida, H.; Imada, Y.; Murahashi, S. I. Biomimetic Flavin-Catalysed Reactions for Organic Synthesis. Org Biomol Chem 2015.

(8) Lechner, R.; Kümmel, S.; König, B. Visible Light Flavin Photo-Oxidation of Methylbenzenes, Styrenes and Phenylacetic Acids. Photochem Photobiol Sci 2010, 9, 1367. 
(9) Schmaderer, H.; Hilgers, P.; Lechner, R.; König, B. Photooxidation of Benzyl Alcohols with Immobilized Flavins. Adv Synth Catal 2009, 351, 163.

(10) Svoboda, J.; Schmaderer, H.; König, B. Thiourea-Enhanced Flavin Photooxidation of Benzyl Alcohol. Chem-Eur J 2008, 14, 1854.

(11) Fukuzumi, S.; Kuroda, S. Photooxidation of Benzyl Alcohol Derivatives By Oxygen, Catalyzed By Protonated Flavin Analogues. Res Chem Intermediat 1999, 25, 789.

(12) Fukuzumi, S.; Yasui, K.; Suenobu, T.; Ohkubo, K.; Fujitsuka, M.; Ito, O. Efficient Catalysis of Rare-Earth Metal Ions in Photoinduced Electron-Transfer Oxidation of Benzyl Alcohols by a Flavin Analogue. J Phys Chem A 2001, 105, 10501.

(13) Tong, W.; Ye, H. P.; Zhu, H. H.; D'Souza, V. T. Photooxidation of Substituted Benzyl Alcohol by Riboflavin. Theochem-J Mol Struc 1995, 333, 19.

(14) Fukuzumi, S.; Tanii, K.; Tanaka, T. Protonated Pteridine and Flavin Analogues acting as Efficient and Substrate-selective Photocatalysts in the Oxidation of Benzyl Alcohol Derivatives by Oxygen. J Chem Soc Chem Comm 1989, 816.

(15) Haas, W.; Hemmerich, P. Flavin-Dependent Substrate Photo-oxidation as a Chemical Model of Dehydrogenase Action. Biochem J 1979, 181, 95.

(16) Feldmeier, C.; Bartling, H.; Magerl, K.; Gschwind, R. M. LED-Illuminated NMR Studies of Flavin-Catalyzed Photooxidations Reveal Solvent Control of the Electron-Transfer Mechanism. Angew Chem Int Ed 2015, 54, 1347. 
(17) Megerle, U.; Wenninger, M.; Kutta, R. J.; Lechner, R.; König, B.; Dick, B.; Riedle, E. Unraveling the Flavin-catalyzed Photooxidation of Benzylic Alcohol with Transient Absorption Spectroscopy from Sub-pico- to Microseconds. Phys Chem Chem Phys 2011, 13, 8869.

(18) Gelalcha, F. G. Heterocyclic Hydroperoxides in Selective Oxidations. Chem Rev 2007, 107,3338 .

(19) Massey, V. Activation of Molecular Oxygen by Flavins and Flavoprotein. J Biol Chem 1994, 269, 22459.

(20) Frederick, R. E.; Mayfield, J. A.; DuBois, J. L. Regulated $\mathrm{O}_{2}$ Activation in FlavinDependent Monooxygenases. J Am Chem Soc 2011, 133, 12338.

(21) Koziar, J. C.; Cowan, D. O. Photochemical Heavy-atom Effects. Acc Chem Res 1978, 11, 334.

(22) Sichula, V.; Kucheryavy, P.; Khatmullin, R.; Hu, Y.; Mirzakulova, E.; Vyas, S.; Manzer, S. F.; Hadad, C. M.; Glusac, K. D. Electronic Properties of N(5)-Ethyl Flavinium Ion. J Phys Chem A 2010, 114, 12138.

(23) Mirzakulova, E.; Khatmullin, R.; Walpita, J.; Corrigan, T.; Vargas-Barbosa, N. M.; Vyas, S.; Oottikkal, S.; Manzer, S. F.; Hadad, C. M.; Glusac, K. D. Electrode-assisted Catalytic Water Oxidation by a Flavin Derivative. Nat Chem 2012, 4, 794.

(24) Li, G.; Glusac, K. D. Light-Triggered Proton and Electron Transfer in Flavin Cofactors. $J$ Phys Chem A 2008, 112, 4573. 
(25) Martin, C. B.; Tsao, M. L.; Hadad, C. M.; Platz, M. S. The Reaction of Triplet Flavin with Indole. A Study of the Cascade of Reactive Intermediates Using Density Functional Theory and Time Resolved Infrared Spectroscopy. J Am Chem Soc 2002, 124, 7226.

(26) Yoshimura, A.; Ohno, T. Quenching of Excited Triplet Lumiflavin by Lumiflavin Radicals Formed in its T-T Reaction. Photochem Photobiol 1991, 53, 175.

(27) Higashimoto, S.; Suetsugu, N.; Azuma, M.; Ohue, H.; Sakata, Y. Efficient and Selective Oxidation of Benzylic Alcohol by $\mathrm{O} 2$ into Corresponding Aldehydes on a TiO2 Photocatalyst Under Visible Light Irradiation: Effect of Phenyl-ring Substitution on the Photocatalytic Activity. J Catal 2010, 274, 76.

(28) S. L. Murov, I. C., G. L. Hug Handbook of Photochemistry; 2nd edn. ed. New York, 1993.

(29) Prier, C. K.; Rankic, D. A.; MacMillan, D. W. Visible Light Photoredox Catalysis with Transition Metal Complexes: Applications in Organic Synthesis. Chem Rev 2013, 113, 5322.

(30) Yoon, T. P.; Ischay, M. A.; Du, J. Visible Light Photocatalysis as a Greener Approach to Photochemical Synthesis. Nat Chem 2010, 2, 527.

(31) Hamilton, D. S.; Nicewicz, D. A. Direct Catalytic Anti-Markovnikov Hydroetherification of Alkenols. J Am Chem Soc 2012, 134, 18577.

(32) Brust, R.; Lukacs, A.; Haigney, A.; Addison, K.; Gil, A.; Towrie, M.; Clark, I. P.; Greetham, G. M.; Tonge, P. J.; Meech, S. R. Proteins in Action: Femtosecond to Millisecond Structural Dynamics of a Photoactive Flavoprotein. J Am Chem Soc 2013, 135, 16168. 
(33) Sancar, A. Cryptochrome: The Second Photoactive Pigment in the Eye and Its Role in Circadian Photoreception. Ann Rev Biochem 2000, 69, 31.

(34) Zhong, D.; Zewail, A. H. Femtosecond Dynamics of Flavoproteins: Charge Separation and Recombination in Riboflavine (Vitamin $\mathrm{B}_{2}$ )-Binding Protein and in Glucose Oxidase Enzyme. Proc Natl Acad Sci 2001, 98, 11867.

\section{Table of Contents Artwork}

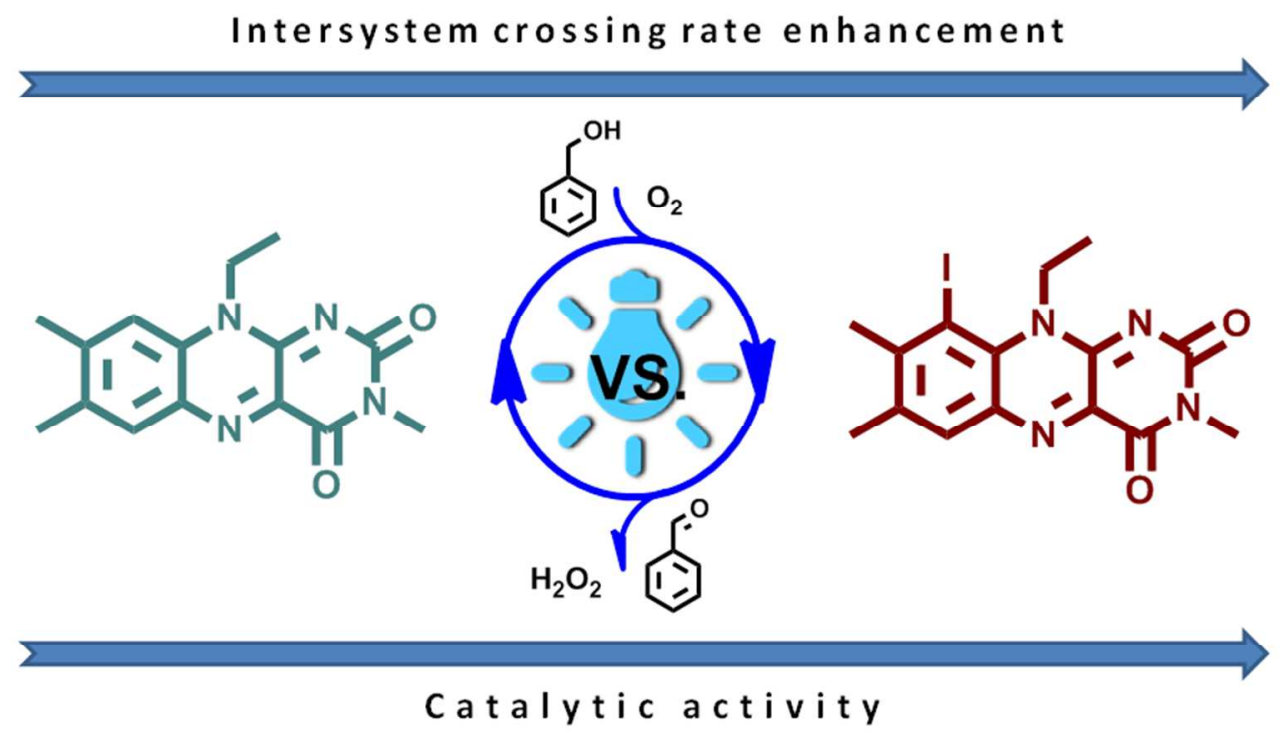

